\title{
Mycotoxigenic Moulds Associated with Coffee and Their Management (A Review)
}

\author{
Demelash Teferi Ashenafi Ayano \\ Jimma Research Center, P. O. Box 192, Jimma; Ethiopia
}

\begin{abstract}
Summary
Coffee is produced in tropical countries where climatic conditions favor mould growth and development. Moulds are multicellular, filamentous fungi that can grow and produce mycotoxins as secondary metabolites on plants either during pre-harvest or post-harvest, storage, transport, processing, and feeding. Mycotoxins are fungal metabolites and chemical defenses that cause lowered performance, sickness or death in human or animals. Aspergillus, Penicillium and Fusarium species are common and important moulds in the human environment and are among the main agents of spoilage of food and feeds. Problems associated with the occurrence of mycotoxins in coffee have become concern to consumers as well as producers. Several studies have reported Ochratoxin A (OTA) presence in raw coffee. OTA is a form of mycotoxin, produced as a metabolic product of Aspergillus ochraceus, Aspergillus carbonarius and strains of Aspergillus niger. Its presence or absence in any sample is probably related to the length of storage rather than to geographical location or other factors. Most importing countries regulate mycotoxins by setting maximum allowable concentration. The European Union (EU) which are among major buyers of coffee from producing countries set maximum permissible limits for OTA of 5 particles per billion (ppb) in roasted and ground coffee, and $10 \mathrm{ppb}$ in instant coffees. This is a serious indicator for coffee producing and selling countries on how they manage their products. Key factors in the successful management of OTA involve good agricultural practices (GAP) and good manufacturing practices (GMP). As it has great influence on countries economy in general and producers income in particular Strict measures should be taken to improve post-harvest handling and processing of coffee, specially drying of bulk coffee along asphalt roads and bare soils should seriously be discouraged. Research is needed on identification of inexpensive and appropriate sampling and testing protocols of mycotoxins associated with coffee in various coffee agro-ecologies and production systems.
\end{abstract}

Keywords: moulds, Ochratoxin A

DOI: $10.7176 / \mathrm{JBAH} / 9-8-06$

Publication date: April $30^{\text {th }} 2019$

\section{Introduction}

Moulds are multicellular, filamentous fungi that can grow and produce mycotoxins as secondary metabolites on plants either during pre-harvest or post-harvest, storage, transport, processing, and feeding (Lacey, 1991). FAO (2007a) estimates show that $25 \%$ of the world's food crops, including many basic foods, are affected by mycotoxin producing fungi. The accumulation of mycotoxins in foods and feeds represents a major threat to human and animal health, as they are responsible for different toxicities including the induction of cancer. Mycotoxins are fungal metabolites and chemical defenses (Abbott, 2002) which, when ingested, inhaled or absorbed through the skin cause lowered performance, sickness or death (Pitt and Hocking, 1997) in man or animals, including birds. Mycotoxins occur in extremely low concentrations (particles per billion (ppb) (Paterson and Bridge, 1994) and are released by relatively few but universally present fungi growing on grains, legumes and nuts. Factors govern the mold invasion and OTA production in foods are water activity, temperature, gas tension specifically of oxygen and carbon dioxide, mechanical damage (Moss, 1991). Moulds normally have the lowest water activity for growth and can grow at water activity of 0.80 or lower hence can grow on partially dehydrated surfaces. Thus care should be taken when handling coffee at all stages in the production chain.

The toxic effect of mycotoxins on animal and human health is referred to as mycotoxicosis. Ergotism (Saint Anthony's fire) of humans and animals, that killed many people in 1978 in Northern Ethiopia (Wollo), and caused by eating ergot containing wheat and rye bread and feeds, consequently poisoning of humans from eating poisonous mushrooms are classic examples of mycotoxicoses (Peraica et al., 1999). Mycotoxicoses are noninfectious, non-communicable, and do not elicit measurable immune response and hence cannot be prevented using medications such as antibiotics, antihistamines, and asthma drugs (Kirkland, 2001).

There have been enormous concerns about mycotoxin especially ochratoxin A (OTA) contamination associated with severe mould growth in coffee. Consequently, great deals of research and extension efforts are being underway globally on mould management (Daniel 2000, Eshetu, 2001, Raghuramulu and Naidu 2002). In this regard, Ethiopian coffee farmers are strongly advised to adopt good harvesting and drying practices to improve quality and reduce mould contamination. Analysis of thousands of coffee samples in different countries revealed that badly processed and handled coffees, irrespective of origin, coffee types and processing methods, possesses OTA (Raghuramulu and Naidu. 2002). Daniel (2000), however, argued that OTA differ across 
geographical regions and processing methods, explaining high OTA risks in East Africa where Arabica coffee is mostly processed by the dry method. Hence, this review paper gives some over views on the nature and importance of mycotoxins in general and association of ochratoxin A (OTA) with coffee as a result of mould contamination in particular.

\section{Research Findings}

\section{Contamination in crops}

Fungi, like all heterotrophic organisms, need water and certain essential nutrients in order to live. Food crops represent a good source of nutrients for the moulds. As moulds grow on these food commodities, they produce secondary metabolites including mycotoxins. Certain fungi have ecological associations with certain crop plants and also certain production, processing or storage conditions favor specific fungi (Frisvad and Thrane, 2000) and hence, certain crops have a tendency to contain particular mycotoxins the production of which depends on the strain and not only the species. Aspergillus, Penicillium and Fusarium species are common and important molds in the human environment and are among the main agents of spoilage in human and animal food. Many species are known to produce a diversity of toxins (Table 1), making them among the most important indoor molds to recover and identify. Carcinogenic effects of inhaling Aspergillus flavus spores have been confirmed by animal studies (Frisvad and Thrane, 2000). Many countries have legislated maximum levels of certain mycotoxins in selected foods to ensure an acceptable level of protection for their citizens against the harmful effects of chronic exposure to these contaminants. On the other hand important aspect to be considered is that the negative publicity surrounding OTA could cause a sharp decrease in consumption, jeopardizing the economic and social conditions of the producing countries (Anzueto, 2002). It now seems clear, however, that coffee is not a major source of OTA in the normal diet (Ministry of Agriculture, Fisheries and Food, 1995). So, creating awareness of the harmful effect level is also the other scenario to maintain the normal market momentum.

Table 1. Moulds and Mycotoxins considered to be of major public health and economic significance worldwide

\begin{tabular}{|c|c|c|}
\hline Mould species & Mycotoxins & Occurrence \\
\hline Aspergillus parasiticus & Aflatoxins $B_{1}, B_{2}, G_{1}, G_{2}$ & $\begin{array}{l}\text { Maize (corn), groundnuts (peanuts), tree nuts, spices, } \\
\text { dried fruit, crude vegetable oils, cottonseed and copra }\end{array}$ \\
\hline Aspergillus flavus & Aflatoxins $\mathrm{B}_{1}, \mathrm{~B}_{2}$ & \\
\hline Fusarium sporotrichiodes & $\mathrm{T}-2$ toxin & Cereals \\
\hline Fusarium graminearum & Deoxynivalenol (DON) & $\begin{array}{l}\text { Grains, especially wheat, barley, oats, rye and maize. } \\
\text { Less often in rice and sorghum }\end{array}$ \\
\hline Fusarium graminearum & Zearalenone & $\begin{array}{l}\text { Maize, but also lower levels in rice, wheat, barley, malt } \\
\text { and soybean }\end{array}$ \\
\hline Fusarium moniliforme & Fumonisin $\mathrm{B}_{1}$ & Maize \\
\hline Penicillium verrucosum & Ochratoxin A (OTA) & $\begin{array}{l}\text { Cereals, fresh grapes, dried vine fruit, wine, beer, } \\
\text { coffee, cocoa }\end{array}$ \\
\hline Aspergillus ochraceus & Ochratoxin A (OTA) & \\
\hline Penicillium expansum & Patulin & $\begin{array}{l}\text { Fresh and processed fruit and vegetables (especially } \\
\text { apples) }\end{array}$ \\
\hline
\end{tabular}

Source: FAO, 2001

\section{Ochratoxin A (OTA)}

Ochratoxin $\mathrm{A}\left(\mathrm{C}_{20} \mathrm{H}_{18} \mathrm{ClNO}_{6}\right)$ is a form of mycotoxin produced as a metabolic product of certain fungi. It is produced by species of two genera of fungi, Aspergillus and Penicillium. Its occurrence has been shown in a variety of unprocessed and processed foods. The main food stuffs contaminated by OTA are cereals and cereal products. Other products that may contain OTA are coffee, beer, pork, blood plasma etc. (Pitt and Hocking, 1997). These commodities contain different concentrations of OTA (Table 2). 
Table 2. Weighted mean concentrations of ochratoxin A in commodities evaluated

\begin{tabular}{lrr}
\hline Commodity & No. of samples & $\begin{array}{r}\text { Weighted mean } \\
\text { concentration }(\mu \mathrm{g} / \mathrm{kg})\end{array}$ \\
\hline Beer & 660 & 0.025 \\
Cereals, all & 2700 & 0.94 \\
Barley & 350 & 0.53 \\
Maize & 95 & 7.5 \\
Oats & 280 & 0.44 \\
Rice & 45 & 0.06 \\
Rye & 790 & 1.2 \\
Wheat & 1200 & 0.38 \\
Cereal products & 1500 & 0.19 \\
Cocoa and chocolate & 270 & 0.18 \\
Coffee, green and roasted & 1900 & 0.86 \\
Green coffee & 130 & 1.0 \\
Roasted coffee & 1700 & 0.76 \\
Instant coffee & 290 & 1.4 \\
Dried vine fruit & 860 & 2.3 \\
Grape juice & 68 & 0.44 \\
Pig kidney & 380 & 0.12 \\
Products of animal origin & 810 & 0.052 \\
(liver, meat, sausages) & & \\
Wine, all & 1800 & 0.32 \\
Red & 1300 & 0.4 \\
White & 260 & 0.1 \\
\hline
\end{tabular}

\section{Source: JECFA, $200 \overline{1}$}

The first reference to OTA in green coffee beans is in Levi et al., (1974) and production of ochratoxin, by Aspergillus ochraceus, was first described in South Africa (Hunter, 1998) while the presence of OTA in samples of commercial roasted coffee was noted by Tsubouchi et al., (1988). OTA derives its name from Aspergillus ochraceus, the mould from which it was first isolated (Naidu, et al., 1997). It is a species complex (Hudler, 1998) and consists of nine species. These species are common in soil, decaying vegetation, and in stored seeds and grains undergoing microbial deterioration.

It is more common in the soil surrounding the roots of coffee trees than in other soils and exposure of coffee flowers to spores of the fungus can lead to infection of the bean (FAO, 2007a). However, the suggestion by Mantle (1998) that ochratoxin A in coffee beans may result from uptake of ochratoxin A in soil by the roots of the coffee tree and then translocation is unsubstantiated (JECFA, 2001). OTA has been shown to be nephrotoxic, hepatotoxic, immuno suppressive, carcinogenic and teratogenic (Peraica et al., 1999) in all monogastric mammalian species tested so far (Kuiper-Goodman and Scott, 1989). However, the mechanism by which ochratoxin A causes carcinogenicity is unknown (JECFA, 2001). In coffee, the most important OTA-producing species or groups of species; A.ochraceus, A. carbonarius and strains of A. niger are of possible significance.

A. ochraceus is well distributed in coffee production systems and appears to be the most prevalent source of ochratoxin A in coffee (Taniwaki et al., 1999). The fungus grows between in temperatures varying between 8 and $37^{\circ} \mathrm{C}$, with the optimum ranging from 24 to $31^{\circ} \mathrm{C}$. Its presence or absence in any sample is probably related to the length of storage rather than to geographical location or other factors (Pitt et al., 1998). A. carbonarius is generally rare, and has been recognized as a source of ochratoxin A only recently (Wicklow et al., 1996). A. carbonarius differs from $A$. niger most notably in the production of larger spores, although other minor morphological differences exist. Preliminary studies (Heenan et al., 1998) indicate that $A$. carbonarius grows at rather lower temperatures than $A$. niger, with a maximum around $40{ }^{\circ} \mathrm{C}$ and optimal conditions about $32-35{ }^{\circ} \mathrm{C}$. A. niger complex is by far the most common, particularly in Coffea caneophora (Robusta), but OTA production is rare and usually feeble. These three groups of species differ in their ecological niches, in the commodities affected, and in the frequency of their occurrence in different geographical regions (JECFA, 2001).

Several studies have reported OTA presence in raw coffee. Research in Thailand (Bucheli et al., 2000) on drying of Robusta coffee has shown that OTA is formed during sun drying in the coffee cherry pericarp. Studies by the Finnish Customs Laboratory also indicated that the overall mean OTA content for the samples of raw coffee was $1.6 \mathrm{ppb}$; whereas over $85 \%$ of the samples were in the lowest category (undetectable up to $2 \mathrm{ppb}$ ) while $1-2 \%$ of the samples were highly contaminated and had a large effect on the overall mean value (FAO, 2005). Studies carried out by Abraham (2006) on the association of ochratoxicogenic fungi on Arabica coffee samples collected from three localities in south west Ethiopia showed high incidence of A. ochraceus on dry processed coffee dried on bare floor than washed coffee on drying beds. Girma and co-workers (2007) reported 
identification of six fungal species belonging to the genera Aspergillus and Penicillium while studying the occurrence and distribution of mould species associated with Ethiopian dried coffee cherry samples collected from the ground and those picked from coffee trees and parchment coffee samples taken from drying tables at Gera, Jimma and Teppi areas (south western Ethiopia). Accordingly, distribution and proportions of these mycofloral populations significantly varied across sample groups and coffee growing areas in the country. $A$. phoenicis was the highest mould species $(65-75 \%)$ isolated in coffee cherries fallen on the ground and dried leftover on the tree at Gera and Jimma. A. melleus was the second highest mould population $(10-50 \%)$ identified in the dried coffee samples collected on the ground and picked on the tree as compared to the washed parchment coffee (Fig. 1). However, none of the OTA forming species, A. ochraceous A. carbonarius and A. niger were isolated from all samples in this study.

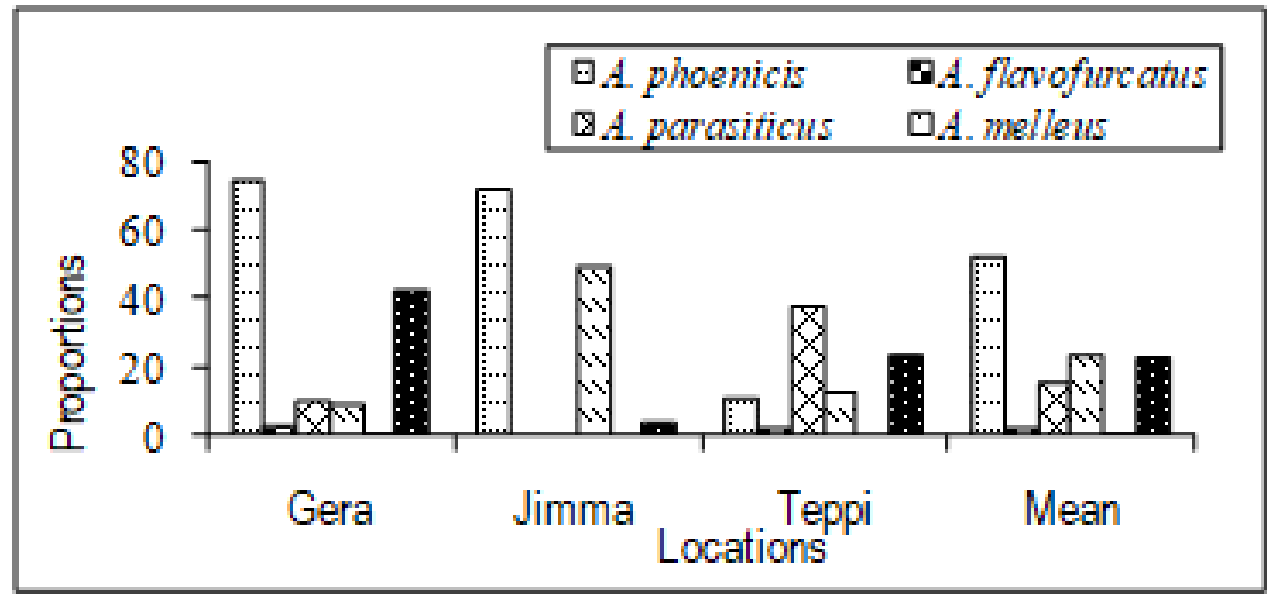

Fig. 1. Distribution of mycofloral species associated with Arabica coffee beans in southwestern Ethiopia. Source: Girma et al. 2007.

Results of Kumi and co-workers (2016), indicated that Aspergillus (70.6\%), Fusarium (15.5\%), Penicillium (11.9\%), with others comprising 2.0\%. was isolated from fresh and dry coffee berries from eight producing locations in the Volta region of Ghana.

Van der Stegen and others (2001) reported that OTA was relatively stable during heat processing; however, toxin levels were reduced $70 \%$ to $96 \%$ during coffee bean roasting, and Heilmann and co-workers (1999) reported similar reductions during roasting (Table 3 ).

Table 3. Reduction in concentrations of ochratoxin A during roasting of coffee

\begin{tabular}{|c|c|c|c|c|}
\hline \multirow[t]{2}{*}{ Sample origin } & \multirow[t]{2}{*}{ Method of contamination } & \multicolumn{2}{|c|}{ OTA concentration $(\mathrm{ng} / \mathrm{kg})$} & \multirow[t]{2}{*}{ Reduction (\%) } \\
\hline & & In green coffee & After roasting & \\
\hline Zaire & Natural & 8.6 & 0.2 & 98 \\
\hline Conillon & Natural & 4.0 & 0.3 & 92 \\
\hline Santos & Spiked & 46 & 6.1 & 87 \\
\hline Costa Rica & Spiked & 42 & 20 & 49 \\
\hline Brazil/Ivory Coast & Spiked & 47 & 11 & 80 \\
\hline Thailand Robusta & Natural & 7.3 & 1.4 & 81 \\
\hline \multirow[t]{5}{*}{ Commercial } & Spiked & 780 & 890 & 0 \\
\hline & Spiked & 1300 & 1200 & 11 \\
\hline & Natural (spoiled) & 360 & 280 & 22 \\
\hline & Natural (spoiled) & 140 & 121 & 16 \\
\hline & Natural (spoiled) & 92 & 92 & 0 \\
\hline \multirow[t]{3}{*}{ Unknown } & Natural & 0.90 & 0.63 & 30 \\
\hline & Natural & 9.9 & 2.1 & 79 \\
\hline & Natural & 18 & 1.9 & 89 \\
\hline Ivory Coast Robusta & Natural & 4.9 & 1.5 & 69 \\
\hline
\end{tabular}

Source: JECFA, 2000.

On the contrary, Viani (1991) reported that OTA is labile, though it could easily be destroyed by high temperature than afflatoxin and sterigmatocystin. Hunter (1998) conducted an experiment with A. ochraceus isolate and determined, the $\mathrm{LD}_{50}$ of ochratoxin for rats to be $22 \mathrm{mg} / \mathrm{kg}$. OTA is so dangerous that FAO/WHO experts have set a maximum tolerable limit for humans of 100 billionths of a gram per kilogram of body weight per week. Similarly, effective as of $1^{\text {st }}$ April 2005, the EU set maximum permissible limits for OTA of 5 ppb in roasted and ground coffee, and $10 \mathrm{ppb}$ in instant coffee. However, there has been no limit so far set for green 
coffee beans (FAO, 2007b).

\section{Mould and OTA management in coffee}

It is generally agreed that preventive measures taken by growers in the coffee production and processing chain are the best way to reduce the incidence of mould formation and the associated risk of OTA contamination. (FAO, 2007b). Key factors in the successful management of OTA involve good agricultural practices (GAP) and good manufacturing practices (GMP) (Naidu 2000; Eshetu, 2001) along the chain. FAO (2007a) reported that through the implementation of GAP and GMP overall levels of OTA fell from a mean of around $2 \mathrm{ppb}$ in the period 1995 to 1998 to less than $1.3 \mathrm{ppb}$ in 2002 to 2004 . Adequately controlling the water available in coffee that could support mould growth and mycotoxin contamination during the post-harvest handling of coffee is the best way to avoid OTA formation. Post-harvest measures include use of drying as dictated by moisture content of the harvested grain, appropriate storage conditions, and use of transport vehicles that are dry and free of visible fungal growth. Studies in Brazil by Taniwaki et al. (1999) have shown that mould growth and ochratoxin A production occur only during drying of green coffee beans and that if drying is rapid and effective OTA will not be produced. Good sun drying or combinations of sun-drying and mechanical dehydration provide effective control. Prevention and periodical surveillance programs are the sole means of controlling quality loss caused by moulds in coffee (Petracco, 1999). No evidence has been found that either A. ochraceus or A. carbonarius invades coffee beans before harvest or has an association with the coffee tree (JECFA, 2001).

\section{Conclusion and Recommendations}

The responsibility of the producing countries regarding OTA problem is clear. They must make extensive efforts to reduce and prevent the development of moulds throughout the coffee supply chain. As it has great influence on countries economy in general and producers income in particular strict measures should be taken to improve post-harvest handling and processing of coffee, specially drying of bulk coffee along asphalt roads and bare soils should seriously be discouraged. Prevention and periodical surveillance programs are the sole means of controlling quality loss caused by moulds in coffee. The influence of roasting is controversial and remains unclear whether OTA in roasted coffee beans can be transferred into the brew. One important aspect to be considered is that the negative publicity surrounding OTA could cause a sharp decrease in consumption, jeopardizing the economic and social conditions of the producing countries. This poses particularly serious problem for countries like Ethiopia where coffee is an important cash crop.

The globalization of trade has complicated the way to deal mycotoxins in that regulatory standards often become bargaining chips in world trade negotiations. While developed countries have well-developed infrastructures for monitoring of internal food quality standards, people in developing countries are not protected by food quality monitoring and enforcement of safe standards within their countries. On the other hand, foods being exported are expected to comply with CODEX Alimentarius standards (2000). The only way-out of OTA contamination in coffee is to strictly adhere and implement good agricultural practices (GAP) and good manufacturing practices (GMP). It now seems clear, however, that coffee is not a major source of OTA in the normal diet. Yet awareness creation and training should be given to coffee growers to improve their understanding of the occurrence and ecology of the fungi that produce OTA in coffee. Incentive payments should be offered to farmers who do apply good practices in the production and handling of coffee, this definitely helps change the behavior of farmers and should be implemented in all coffee growing countries. Close supervision and preventive measures should be taken by development agents and other concerned government bodies on drying and processing coffee. Preventative measures should be taken by all participants in the coffee value chain are the best way to reduce the incidence of mold formation in coffee and associated risk of OTA contamination. Research is needed on identification and application of appropriate technologies for obtaining low bean moisture at harvest and in storage. Identifying inexpensive and appropriate sampling and testing protocols is also required.

\section{References}

Abbott, S.P. 2002. Mycotoxins and Indoor Moulds. Indoor Environment Connections, 3:14 - 24

Abraham, T. 2006. A study on ochratoxin A and ochratoxigenic fungi in coffee. M.Sc. thesis, Addis Ababa University, Ethiopia.

Anzueto, F. 2002. Control of Ochratoxin A in Coffee to Meet the Standards of Importing Countries: The Guatemalan Experience.E. Hanak, E. Boutrif, P. Fabre, M. Pineiro, (eds), 2002. Food Safety Management in Developing Countries. Proceedings of the International Workshop, Montpellier, France.

Bucheli, P., Kanchanomai, C., Meyer, I. and Pittet, A. 2000. Development of ochratoxin A during robusta (Coffea canephora) coffee cherry drying. J. Agric. Food Chem., 48:1358 - 1362.

CODEX Alimentarius Commission. 2000. Proposed Draft Code of Practice for the Prevention of Contamination by Ochratoxin A in Cereals. CX/FAC00/17, Rome. 
Eshetu Derso. 2001. Mycotoxins in Coffee: A Review. Coffee and Tea .2001, vol.12, P.40-46 Coffee and Tea Authority. Addis Abeba, Ethiopía.

FAO. 2001. Food and Nutrition Papers 73. Manual on the application of the HAACCP system in mycotoxin prevention and control.

FAO/WHO Joint experts committee on food additives (JECFA). 2000. Ochratoxin A, JECFA 46, evaluation.

FAO/WHO Joint experts committee on food additives (JECFA). 2001. Ochratoxin A, JECFA 47, evaluation.

FAO. 2006. Food and Nutrition Papers 73. Manual on the application of the HAACCP system in mycotoxin prevention and control.

FAO. 2005. Post-harvest handling and processing of coffee in African countries. Corporate document repository. (http://www.ars.usda.gov.)

FAO.2007a. Food safety and quality. Nutrition and consumer protection division (http://www.fao.org/ag/agn/index_en.stm .)

FAO, 2007b. Guidelines for the Prevention of Mould Formation in Coffee.pdf. Final document, pp. $1-25$.

Frisvad, J. and U. Thrane. 2000. Mycotoxin production by common filamentous fungi. In: Introduction to foodand airborne fungi. CBS, Utrecht, Netherlands.

Girma, A.; Nirenberg, H., Hindorf, H. 2007. Detection and enumeration of mycofloral populations associated with Ethiopian Arabica coffee bean contamination. : Proceedings of $21^{\text {st }}$ International Scientific Conference on Coffee Science (ASIC)conference, 11 - 15 September 2006, Montpellier, France. Pp 503 - 509.

Heenan, C.N., Shaw, K.J. and Pitt, J.I. 1998. Ochratoxin A production by Aspergillus carbonarius and A. niger isolates and detection using coconut cream agar. J. Food Mycol., 1 : 67-72.

Heilmann W, Rehfeldt AG, Rotzoll F.1999. Behavior and reduction of ochratoxin A in green coffee beans in response to various processing methods. EurFood ResTechnol 209:297 - 300.

Hudler, G. 1998. Magical and Mischievous Molds. Princeton University Press. 248 pp.

Hunter, B.T., 1998. Mycotoxins: A Significant Public Health Problem. Consumer's Research 72 (6)8-9.)

Kirkland, K. 2001. Health hazards from exposure to mycotoxic fungi in indoor environments. The Synergist Apr: $25-26$.

Kuiper-Goodman, T. and Scott, P.M. 1989. Risk assessment of the mycotoxin ochratoxin A. Biomed. Environ. Sci., 2: 179-248.

Kumi Winifred O., I. Attah Amoako-, Lowor S. T., Takrama J. F. and Ansah F. Owusu 2016. Mycotoxigenic moulds associated with coffee berries in the Volta region, Ghana .pp112-120. In Bayetta Belachew (ed). Coffee research and regional project results dissemination workshop in Africa 23 - 27 November 2015, Luanda, Angola .

Levi, C., Trenk, H.L., Mohr, H.K., 1974. Study of the occurrence of ochratoxin A in green coffee beans. Journal of the AOAC, 57: $866-870$.

Lacey, J. (1991). Natural occurrence of mycotoxins in growing and conserved forage crops. J. E. Smith and R. E. Henderson (Eds.). Mycotoxins and Animal Foods. CRC Press, Boca Raton, Fla., Pg 363 - 397 Mantle, P.G. 1998. Ochratoxin A in coffee. Food Mycol., 1: 63-65.

Ministry of Agriculture, Fisheries and Food .1995. Surveillance of Ochratoxin A in Retail Coffee Products (Food Surveillance Information Sheet No. 73), London: Joint Food Safety and Standard Group.

Moss, 1991 .The environmental factors controling mycotoxin formation. In: Mycotoxins and Animal foods (Smith, J.E and Henderson R.S. eds) CRC Press Boca Raton, Florida.

Naidu, R.S. Daivasikamani, J.S Nagaraj. 1997. Current status and strategies for management of mycotoxins in India coffees. Pp. $69-78$. Proceedings of $17^{\text {th }}$ Association Scientifique International du café (ASIC) 20 25 June, 1997, Nairobi, Kenya.

Paterson, R.R.M. and Bridge, P.D. 1994. Biochemical techniques for filamentous fungi. IMI Technical Hand book NO. 1., CABI: Wallingford 125pp.

Peraica, M.; Radic, B.; Lucic, A. and Pavlovic, M. 1999. Diseases Caused by Molds in Humans. Bulletin of the World Health Organization

Petracco, M., 1999. Melhoramento da Qualidade do Café pelo Combate ao Crescimento de Mofos. In: I Simposio sobre calidade y produtividade do café. Universidade Federal de Viçosa, M.G.,Brasil, setembro de 1999, pp. 22-38.

Pitt, J.I. and Hocking, A.D. 1997. Fungi and Food Spoilage, 2nd Ed., Gaithersburg, MD: Aspen Publishers.

Pitt, J.I., Hocking, A.D., Miscamble, B.F., Dharmaputra, O.S., Kuswanto, K.R., Rahayu, E.S. and Sardjono. 1998. The mycoflora of food commodities from Indonesia. J. Food Mycol., 1: 41-60.

Raghuramulu, Y. and R. Naidu. 2002. The Ochratoxin-A contamination in coffee and its significance in food safety issues. Indian Coffee.

Taniwaki, M.H., Pitt, J.I., Urbano, G.R., Teixeira, A.A. and Leitão, M.F.F. 1999. Fungi producing ochratoxin A in coffee. Proceedings of the 18th International Scientific Colloquium on Coffee, Helsinki, Finland, 2-6 August, 1999, pp. 239-247. 
Tsobouchi. T., Terada. H., Yamamoto. K., Hisadak. K., Sakabe. Y. 1988. Ochratoxin A found in commercial roast coffee. J. Agric. Food Chem. 36: 540-542.

Van der Stegen GH, Essens PJ, van der Lijn J. 2001. Effect of roasting conditions on reduction of ochratoxin A in coffee. J Agric Food Chem 49: 4713-4718.

Wicklow, D.T., Dowd, P.F., Alfatafta, A.A. and Gloer, J.B. 1996. Ochratoxin A: An antiinsectan metabolite from the sclerotia of Aspergillus carbonarius NRRL 369. Can. J. Microbiol., 42: 1100 - 1103. 